\title{
Energy performance evaluation of a demo solar desiccant cooling system with heat recovery for the regeneration of the adsorption material
}

\author{
Marco Beccali*, Pietro Finocchiaro, Bettina Nocke \\ Dipartimento dell'Energia, Università degli Studi di Palermo, Via delle Scienze bld. 9, 90128 Palermo, Italy
}

\section{A R T I C L E I N F O}

\section{Article history:}

Received 17 November 2010

Accepted 27 December 2011

Available online 2 February 2012

\section{Keywords:}

Solar cooling

Desiccant evaporative cooling

Integrated heat pump

Primary energy savings

\begin{abstract}
A B S T R A C T
Since July 2008, a Solar Desiccant Evaporative Cooling (DEC) system has been operating as a test plant at the solar laboratory of the Dipartimento di Energia (ex DREAM) of the University of Palermo. The system is composed of an air handling unit (AHU) designed for ventilation of the laboratory coupled with a radiant ceiling that provides most of the required sensible cooling/heating energy. Flat plate collectors deliver part of the regeneration heat of the desiccant wheel during the summertime and are used for space heating during the wintertime.

The system was designed for high humidity loads because of the typical climate conditions at the site and the need to support a radiant ceiling for sensible cooling. A hybrid configuration was chosen that uses two auxiliary cooling coils fed by a conventional compression chiller. One coil is used for predehumidification. The other coil controls the air temperature if the desired supply temperature cannot be reached through indirect evaporative cooling alone. A specific feature of the system is the use of the heat rejected by the chiller to preheat regeneration airflow.

The plant was monitored continuously after installation and start up phases were completed. This paper presents instantaneous, daily and monthly energy performance indicators for five summer months and three winter months. Monthly results are also presented and elaborated upon according to a monitoring procedure developed in the framework of the International Energy Agency (IEA) Task 38 "Solar Air Conditioning and Refrigeration" of the Solar Heating and Cooling Programme. Seasonal performance indicators such as electric and thermal COP and primary energy savings for cooling and heating operation are presented. It was found that about half of the total cooling energy delivered by the AHU was covered by the DEC process. Primary energy savings in summer, in comparison to a conventional AHU, came up to nearly $50 \%$.

The recovery of the heat rejected by the refrigerator was found as a good solution, permitting to reduce solar collector area in the design phase.

Finally, main issues arisen from plant monitoring and possible solutions to enhance its energy performances are discussed.
\end{abstract}

(c) 2012 Elsevier Ltd. All rights reserved.

\section{Introduction}

Desiccant Evaporative Cycles (DEC), patented and improved since the middle of the last century, are thermally driven air conditioning processes usually based on a combination of adsorptive dehumidification and evaporative cooling $[1,2]$. The heart of this technology is the dehumidification wheel, a matrix with a highly porous structure that captures the vapour molecules of an air stream on one side and transfers this humidity to a hot air stream on the other side (regeneration air). Solar energy can be used as the

\footnotetext{
* Corresponding author. Tel.: +39 (0) 91238911; fax: +39 (0) 91484425

E-mail address: marco.beccali@dream.unipa.it (M. Beccali).
}

driving heat, leading to interesting possibilities when the cooling loads of a building coincide with the availability of solar radiation.

Silica gel, lithium chloride and zeolites are the most commonly used adsorptive materials. Henning gives an overview of European research on solar-assisted air conditioning up to 2005 [3,4]. Mazzei et al. present a theoretical and critical review of HVAC dehumidification systems for thermal comfort, including solid sorption cycles [4,5].

The use of solar desiccant systems presents some technical limitations in hot and humid climates, mainly due to the high latent loads handled by the wheel, and the reduced potential of evaporative cooling [6-8]. Specific sequences of air treatments can be implemented to cope with these conditions and to improve the effectiveness of the cycle [9-11]. 


\begin{tabular}{|c|c|c|c|}
\hline \multicolumn{2}{|c|}{ Nomenclature } & SF & Solar Fraction \\
\hline$E_{e l}$ & Electricity consumption [kWh] & \multicolumn{2}{|c|}{ Greek letters } \\
\hline$\Delta H_{A H U}$ & Total Enthalpy difference in the AHU [kWh] & $\eta_{\text {storage }}$ & Hot storage efficiency [-] \\
\hline$h_{\text {in } A H U}$ & Specific enthalpy of outside air [kJ/kg] & $\eta_{\text {heat }}$ & Solar heat management efficiency [-] \\
\hline$h_{\text {out } A H U}$ & Specific enthalpy of supply air [kJ/kg] & $\eta_{\text {boiler }}$ & Gas heater efficiency [-] \\
\hline$\dot{m}$ & Supply airflow rate $[\mathrm{kg} / \mathrm{h}]$ & $\varepsilon_{\text {fossil }}$ & Primary energy factor for fossil fuel $[-]$ \\
\hline PER & Primary Energy Ratio [-] & $\varepsilon_{\text {elec }}$ & Primary energy factor for electricity prod. $[-]$ \\
\hline \multicolumn{4}{|c|}{ Qut storage Heating energy delivered by the hot storage [kWh] } \\
\hline$\Delta t$ & Time interval $[\mathrm{h}]$ & \multicolumn{2}{|c|}{ Subscripts } \\
\hline AHU & Air Handling Unit & EXT & external \\
\hline DW & Desiccant wheel & $R E G$ & regeneration \\
\hline $\mathrm{CC}$ & Cooling Coil & $B U I$ & Building \\
\hline $\mathrm{HC}$ & Heating Coil & $s p$ & Set point \\
\hline HU & Humidifier & th & thermal \\
\hline HX & Sens. Heat Exchanger & el & electrical \\
\hline
\end{tabular}

Some experimental DEC plants have been installed in recent years. Monitoring these systems is an important task to investigate the actual performance of this technology under different conditions. Successful monitoring is one of the issues presented in the IEA Task 38 "Solar Air Conditioning and Refrigeration". First results of this research activity were presented for medium-scale, solarassisted desiccant cooling systems in the town halls in Gleisdorf (Austria) and Ingolstadt (Germany), both showing acceptable performances but lower than expected [12,13]. Frequent problems and malfunctions of the monitored systems were due to lower than expected efficiencies of single components for such heat exchangers, and weak spots such as air leakages, moisture carryover, the control strategy of the system and parasitic electricity consumption. Bourdoukan et al. presented studies based on an experimental investigation conducted at a test facility for DEC systems, which determined the most influential parameter on energy performance related to operating conditions is the outside humidity ratio [14]. In particular, it was shown that an increase in the humidity ratio of outside air decreased both the dehumidification potential of the desiccant wheel, and the cooling capacity of the DEC process. This emphasizes the need to find special solutions for DEC systems operating in hot and humid climates.

The monitoring results for an operation period between July 2008 and January 2010 are presented in this study. Both cooling and heating periods can give insight into the potential and limits of this configuration, as well as possible improvements.

\section{System design}

The system studied in this paper was designed for scientific purposes, with the aim to test its energy performance in relation to the following main aspects:

- High dehumidification requirements (outside air humidity ratio of the site can be very high in the summer season, with peaks over $20 \mathrm{~g} / \mathrm{kg}$, while the required supply humidity ratio is below $8 \mathrm{~g} / \mathrm{kg}$ )

- The exploitation of the rejected heat from the chiller to preheat the regeneration airflow

- The coupling with a radiant ceiling

The task of the AHU is the conditioning of primary air with a ventilation flow rate of $1250 \mathrm{~m}^{3} / \mathrm{h}$ system was designed using a detailed simulation process on the TRNSYS platform [9,15-17]. This process developed a complete mathematical model, including weather data processing, reference-building latent and sensible loads, AHU components, solar collectors, auxiliaries and control strategy.

The total rated cooling load both for ventilation and sensible cooling is $28 \mathrm{~kW}$, calculated according to peak summer outdoor conditions of $38{ }^{\circ} \mathrm{C}$ and $50 \% \mathrm{RH}$ and indoor conditions of $26^{\circ} \mathrm{C}$ and $50 \% \mathrm{RH}$. The portion of the load covered by the radiant ceiling is about $6 \mathrm{~kW}$. Total heating load amount to $11 \mathrm{~kW}$, according respectively to outdoor and indoor temperature of $5^{\circ} \mathrm{C}$ and $20^{\circ} \mathrm{C}$.

It must be underlined that the whole system is designed for cooling purposes, being the cooling demand more than 2.5 times the heating one.

The system operated almost year round, except in April, October and November. The daily operation time period was from 7:00 AM to 7:00 PM (8:00 AM to 6:00 PM in the winter) every day of the week.

Figs. 1 and 2 show the system configuration and its main components, as well as the thermodynamic cycles in the psychrometric chart for summer and winter operation.

In the summer season, the desiccant cooling unit provides air change and dehumidification by means of a desiccant wheel regenerated both from solar collectors and from the rejected heat of the chiller. Therefore, thermodynamic heat recovery occurs by using the condensation heat of the water chiller which feeds the radiant ceiling and the auxiliary cooling coils (CC1 and CC2) of the desiccant unit.

The first coil, CC1, is utilized for pre-dehumidification purposes (air-treatment 1-2 in Fig. 2a). In example case shown in Fig. 2a, air enters in the desiccant wheel where it is further dehumidified and heated up to point 3.In this process the enthalpy of the air is slightly increased. In the sensible heat exchanger the air is cooled down (3-4). The second coil, CC2, controls the supply air temperature if the indirect evaporative cooling process is not sufficient to reach the desired value (line $4-5$ in Fig. 2a), Return air from the building (point 6 in Fig. 2a) gets close to saturation in the humidifier (7), in order to perform a maximal heat recovery in the heat exchanger (7-8).

The heat rejected by the chiller is used in the return-side process to preheat the regeneration air stream, increasing its temperature by about $12-15{ }^{\circ} \mathrm{C}$ (8-9 in Fig. 2a). An external condenser connected in series to the heat-recovery coil permits the remaining condensation of the refrigerant. A further temperature increase occurs in the solar coil HC2 (9-10) linked to the solar loop, which results in the regeneration air temperature at the inlet of the desiccant rotor.

The average air mass flow rate between regeneration air and process air is 0.65 . 

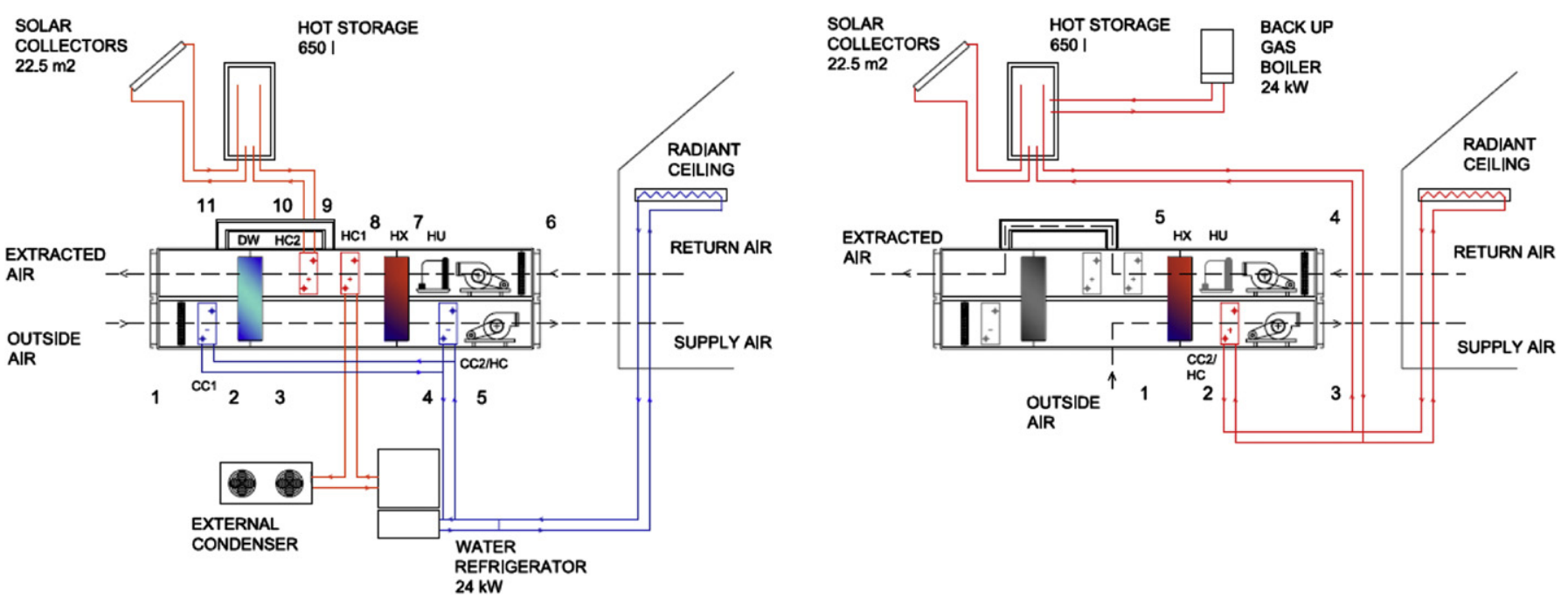

Fig. 1. Functional scheme- summer operation (left) and winter operation (right).

A heat storage tank of $0.65 \mathrm{~m}^{3}$ balances the heat produced by the solar system and the heat supplied to the coil HC2. Any hot backup device is used in the summer season.

In the winter season, the humidifier is not operating, and a heat recovery (1-2 in Fig. $2 b$ ) is carried out in the sensible heat exchanger. The radiant ceiling is also used for heating purposes, being most of the heat delivered in radiant rather than in convective form. Supply air enters the room across the holes of the ceiling, reducing the effect of air stratification. The radiant ceiling and the CC2 (as a heating coil, 2-3 in Fig. 2b) are fed by the solar heat. A gas boiler is now used as a backup heat source.

Table 1 shows a list of the main components of the plant with design data.

\section{Control strategy}

The first task of the control strategy is to set the general operation cycle of the whole system (cooling, heating or ventilation) according to the outside temperature. The general operation cycle is set to heating if the outside temperature is lower than $20^{\circ} \mathrm{C}$, whereas to cooling if higher than $24^{\circ} \mathrm{C}$. In heating cycle, the gas boiler is made available, the chiller is set off, the radiant ceiling is operated in winter mode whereas the AHU can be operated in MODE from 0 to -2 (see below). In cooling cycle, the chiller is made available, the radiant ceiling is operated in summer mode whereas the AHU can be operated in MODE from 0 to 3 . Between these thresholds, the control strategy is set to the ventilation cycle, where both chiller and boiler are set off and only the fans of the AHU are switched on. Afterwards, the control sets the specific operation mode of the AHU (MODE) according to the indoor conditions (see Fig. 3). Independently of the general cooling or heating cycle of the system, the AHU is started in ventilation mode (MODE 0). After a dead time of $15 \mathrm{~min}$, the control strategy changes the MODE if the indoor conditions are not guaranteed.

For example, if the outside temperature drops below $20^{\circ} \mathrm{C}$, the control strategy sets the general operation cycle of the system to heating. In this case, AHU can be operated in MODE from 0 to -2 according to the indoor air conditions. As long as the indoor air temperature is within the desired range, the AHU will stay in ventilation mode (MODE 0 ).

To reduce electricity consumption, fans are controlled by two inverters, and an additional air intake, placed downstream of the desiccant wheel, permits to reduce pressure drops during ventilation and heating operation.

The control of the AHU for the cooling cycle has three further operation modes:

MODE 1. (Indirect evaporative cooling)

In this mode of operation, only indirect evaporative cooling is performed, using the heat exchanger HX and the humidifier on the
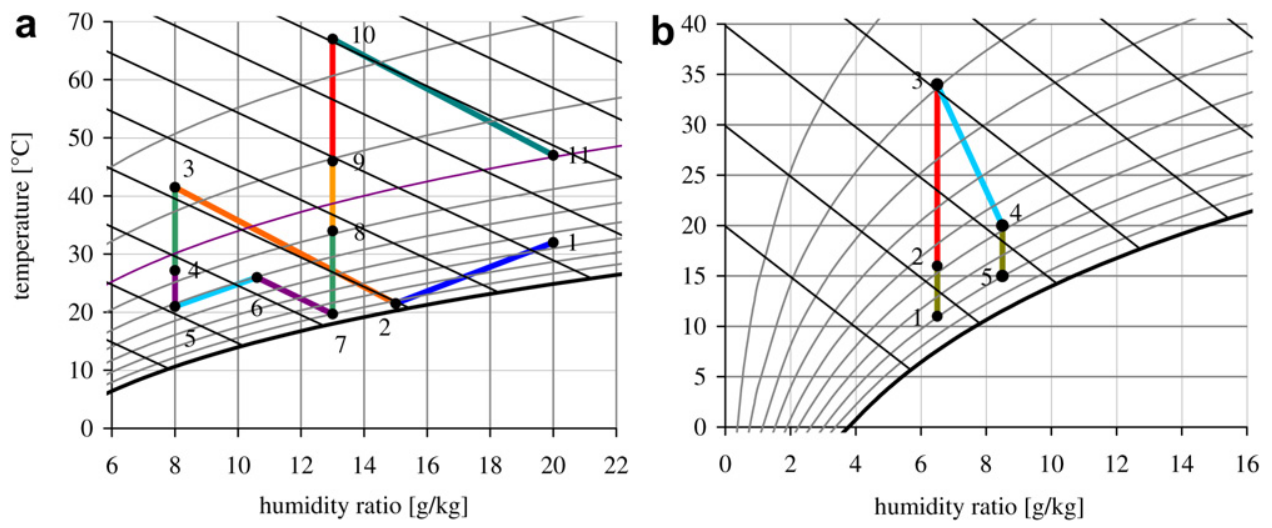

Fig. 2. Psychrometric chart - a) summer operation (left) and b) winter operation (right). 
Table 1

Design data of main components installed in the system.

\begin{tabular}{|c|c|c|}
\hline Component & Description & Project data \\
\hline \multicolumn{3}{|l|}{ Air handling unit of $1250 \mathrm{~m}^{3} / \mathrm{h}$} \\
\hline \multirow[t]{7}{*}{ Desiccant wheel } & Silicagel, & Rated air conditions indicated \\
\hline & $D=700 \mathrm{~mm}, W=200 \mathrm{~mm}$ & from the producer: \\
\hline & Rotational speed: $15 \mathrm{rev}^{-1}$ & $T_{\text {ext }}=30^{\circ} \mathrm{C}, x_{\text {est }}=16 \mathrm{~g} / \mathrm{kg}$ \\
\hline & & $T_{\text {reg }}=60^{\circ} \mathrm{C}, x_{\text {reg }}=16 \mathrm{~g} / \mathrm{kg}$ \\
\hline & & Rated process airflow: $2500 \mathrm{~m}^{3} / \mathrm{h}$ \\
\hline & & Process/regeneration airflow: 3:2 \\
\hline & & Dehumidification capacity $4 \mathrm{~g} / \mathrm{kg}$ \\
\hline \multirow[t]{2}{*}{ Heat exchanger } & Rotary heat exchanger (aluminium rotor) & Cooling capacity: $10 \mathrm{~kW}$ \\
\hline & Rotational speed: $600 \mathrm{rev} \mathrm{h}^{-1}$ & Efficiency: 0.68 \\
\hline Humidifier & Packaged humidifier & Efficiency: 0.83 \\
\hline \multirow[t]{2}{*}{ Cooling coils } & Conventional cross flow cooling coil & CC1: $16 \mathrm{~kW}$ \\
\hline & & CC2: 6 kW (only sensible cooling) \\
\hline \multirow[t]{2}{*}{ Heating coils } & Conventional cross flow cooling coil & HC1: 6 kW (refrigerant cycle) \\
\hline & & HC2: $12.5 \mathrm{~kW}$ (solar cycle) \\
\hline Fans & Variable airflow rate (inverter) & Nominal airflow rate: $1250 \mathrm{~m}^{3} / \mathrm{h}$ \\
\hline \multicolumn{3}{|l|}{ Solar system } \\
\hline Flat plate solar collectors & Selective surface middle performance class & Absorber surface $22.5 \mathrm{~m}^{2}$ azimuth: $0^{\circ}$, tilt $34^{\circ}$ \\
\hline Heat storage & Global heat transfer coefficient $2 \mathrm{~W} / \mathrm{m}^{2} \mathrm{~K}$ & Capacity: 6501 \\
\hline \multicolumn{3}{|l|}{ Auxiliary chiller/auxiliary heater } \\
\hline $\begin{array}{l}\text { Water chiller (Evaporating unit) } \\
\text { with external condenser }\end{array}$ & On-off control & $\begin{array}{l}\text { Cooling Capacity } 24.3 \mathrm{~kW} \\
\text { COP } 3.47 \text { (rated) }\end{array}$ \\
\hline Auxiliary gas heater & Fuel: GPL & Nominal Heating Power: $24 \mathrm{~kW}$ \\
\hline
\end{tabular}

return side $\mathrm{HU}$. The humidifier on the return side always operates at full power. Since the humidity ratio of the outside air is normally high and the required humidity ratio of the supply air is very low, no humidifier on the supply side is needed. Supply air intake is lateral, downstream of the desiccant wheel. The bypass around the desiccant wheel is open.
MODE 2. (Desiccant cooling)

In the solar desiccant cooling cycle, the desiccant wheel is regenerated by means of the heat provided by solar collectors and the condenser of the chiller. The heat exchanged in the recovery coil $\mathrm{HC} 1$ is provided by the condensation of refrigerant in the chiller at the compressor outlet. There is no special control of the heating

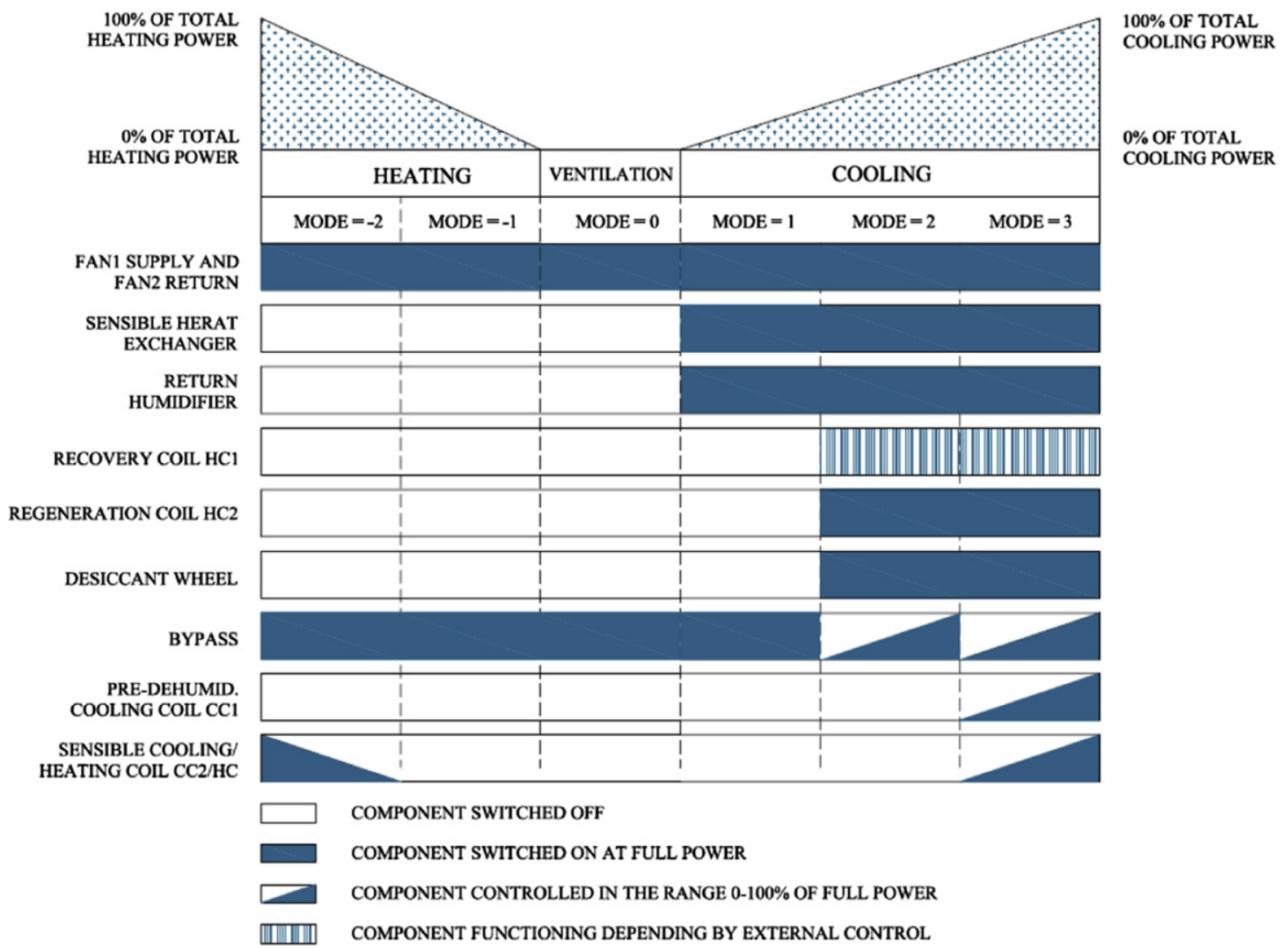

Fig. 3. Detailed control sequence diagram. 
power of this coil; it only depends on the internal control of the chiller. Since the cooling machine provides cooling not only to the auxiliary cooling coils, but also to the radiant ceiling, which has its own control, condensation heat is often available.

The ratio of process and regeneration airflow in the desiccant wheel can be varied using the bypass duct, with normal ranges from $2: 3$ to $1: 1$, since the regeneration temperature is not very high (max value registered was about $68^{\circ} \mathrm{C}$ ). No direct control of the dehumidification capacity of the desiccant wheel is performed (regeneration temperature is always the highest possible, and the bypass is not continuously modulated as conditions change).

MODE 3. (Aux cooling)

The auxiliary backup coils CC1 and CC2 are both activated in order to meet the cooling loads when the desiccant cycle is not able to reach the desired supply air conditions. The first coil, CC1, is activated and controlled to maintain a room humidity ratio of $10.5 \mathrm{~g} / \mathrm{kg}$, corresponding to a relative humidity of $50 \%$ at $26^{\circ} \mathrm{C}$. The second coil, CC2, is activated and controlled to reach a supply air temperature of $18-24{ }^{\circ} \mathrm{C}$. The set point chosen for the supply temperature is quite low due to the limited cooling power of the chilled ceiling, which normally cannot meet the entire sensible cooling load of the building.

The control of the AHU for the heating cycle has two additional operation modes:

MODE -1. (Heat recovery)

In this mode of operation, heat recovery from the return air is accomplished using the sensible heat exchanger HX. Supply air intake is lateral, downstream of the desiccant wheel, and the bypass of the desiccant wheel is $100 \%$ open.

MODE -2. (Active heating)

In addition to the heat recovery process, the coil $\mathrm{HC}$ is activated to provide heat from the storage to the supply air stream (CC2 and HC is the same coil). A set point of $30^{\circ} \mathrm{C}$ for the supply temperature is used. A gas boiler is used in the winter season if the required temperature in the storage cannot be achieved by the solar collectors.

Fig. 3 shows a scheme of the operation modes of the AHU set by the control strategy.

\section{Measurement and data acquisition equipment}

To fulfil the tasks of data acquisition, monitoring and system control, a multi-channel data logger Yokogawa MX 100 was programmed on the LabVIEW platform. The type, number and displacement of the sensors installed for the monitoring of performance indicators of the system have been chosen according to the recommendations included in the guidelines and monitoring procedures of Task 38 "Solar Air Conditioning and Refrigeration" of IEA. In total, 48 measurement points were connected to the monitoring system.

In order to measure temperatures inside the AHU, PT100 class-A sensors were used (accuracy $\pm 0.15{ }^{\circ} \mathrm{C}$ ). For measurements of air humidity, temperature-humidity transmitters with an accuracy of $0.3{ }^{\circ} \mathrm{C} / \pm 2.5 \%$ were used. In the air ducts, temperature, relative humidity and air speed transmitters (active hotwire) were used, with an accuracy of $0.2 \mathrm{~m} / \mathrm{s}+3 \%$ of measured value, which also allowed supply and return air mass flow rates to be calculated.

In the hydraulic loop, temperatures were measured with PT100 sensors with accuracy of $\pm 0.15^{\circ} \mathrm{C}$. Ultrasonic flow meters with $2.5 \%$ accuracy were chosen for hot-water loops (solar and boiler circuit), and axial turbine-flow sensors (accuracy 3\%) were installed in the circuits of the chiller, auxiliary boiler and radiant ceiling.

Solar radiation was measured using a pyranometer (1st class, ISO 9060) installed on the collector plane.
In order to measure electricity consumption, four energy meters were installed, one for each of the following functional groups:

- Water chiller loop

- AHU (fans, pump for humidifier, motors for the desiccant and heat recovery rotor)

- Auxiliaries (pumps, actuators, etc.)

- Radiant ceiling loop

\section{Performance indicators of monitoring results}

Monitoring data were acquired and stored with a five-minute time step. Instantaneous, daily and monthly performance of single components and functional groups were calculated. The monitoring data discussed in this work are for five summer months and three winter months between 2008 and 2010, including both cooling and heating modes, and excluding the months of March, April, October and November. Midseason performance evaluation was not included because the relatively low cooling and heating loads would not be indicative of the system's true capabilities.

The total cooling/heating power of the AHU $\left(P_{A H U}\right)$ can be defined by the following formula:

$P_{A H U}=\frac{\left|\dot{m}\left(h_{\text {in } A H U}-h_{\text {out } A H U}\right)\right|}{3600}[\mathrm{~kW}]$

The contribution of desiccant cooling to the total cooling power $\left(P_{D E C}\right)$ from both the desiccant wheel and indirect evaporative cooling processes can be calculated as the difference between the total AHU power and the cooling power of auxiliary coils:

$P_{D E C}=P_{A H U}-P_{C C \text { aux }}[\mathrm{kW}]$

The thermal power of the solar collector $P_{\text {coll }}$ was calculated from measured inlet and outlet water temperatures and flow mass rate. Cold production of the auxiliary chiller can be calculated in a similar way.

In all the energy balance calculations, only the operation time period was considered, except for the calculation of heat loss in the storage and the external collector pipe line.

Several efficiency indicators can be used to describe system performance:

- Thermal COP of the DEC process

$C O P_{t h}=\frac{P_{D E C}}{P_{\text {reg }}}[-]$

where $P_{\text {reg }}$ can refer to either the whole regeneration heat (contribution of heating coils HC1 and HC2 to heating the regeneration flow stream) or to only the contribution of the solar coil HC2. It is measured from the air upstream and downstream of the coils.

- Electric COP of the AHU

$\mathrm{COP}_{e l}=\frac{P_{A H U}}{P_{\text {el }} \text { tot } A H U}[-]$

where $P_{A H U}$ is the cooling/heating power delivered by the AHU, and $P_{e l}$ tot $A H U$ is the electric power of the AHU due to fans, cold production of the chiller for the cooling coils and accessories.

- Efficiency of solar collectors

$\eta_{\text {coll }}=\frac{P_{\text {coll }}}{I_{\text {sol }}}[-]$ 
where $P_{\text {coll }}$ is the collector power and $I_{\text {sol }}$ is the total solar radiation measured on the collector plane in $\mathrm{kW}$.

Daily/Seasonal Solar Fraction

$S F=\frac{Q_{\text {coll }}}{Q_{\text {coll }}+Q_{\text {fossil }}}[-]$

where $Q_{\text {coll }}$ is the heat delivered to the storage by solar collectors and $Q_{\text {fossil }}$ is the heat delivered by the auxiliary gas boiler.

Daily/Seasonal storage efficiency

$\eta_{\text {storage }}=\frac{Q_{\text {heat }, \text { reg }}+Q_{\text {heat }, \text { build }}}{Q_{\text {coll }}+Q_{\text {fossil }}}[-]$

where $Q_{\text {heat,reg }}$ is heating energy used for regeneration and $Q_{\text {heat,build }}$ is space heating.

- Daily/Seasonal Solar heat management efficiency

$\eta_{\text {heat }}=\frac{Q_{\text {tot heat }, \text { useful }}}{Q_{\text {sol }}}[-]$

where $Q_{\text {tot heat,useful }}$ is the total heat energy leaving the hot storage.

\section{Summer operation: monitoring results for instantaneous, daily and monthly performance}

Figures for instantaneous, daily and monthly performance indicators, such as cooling power and regeneration heat, are presented and discussed here. These detailed energy performance data can lead to a better understanding of specific issues in operation and the implemented control strategy.

In this analysis, focus is on the desiccant cooling process. Thus, system boundaries for cooling do not consider energy flows related to the radiant ceiling which is fed by the conventional chiller.

During a typical summer day, as shown in Fig. 4, the predehumidification coil CC1 switches on when the indoor absolute humidity exceeds the threshold of $10.5 \mathrm{~g} / \mathrm{kg}$. Supply temperatures without the cooling coil CC2 range between 27 to just below $24^{\circ} \mathrm{C}$, with a minimum value of $23.9^{\circ} \mathrm{C}$ between 6:00 and 7:00 PM. The sensible cooling load can then be met by the radiant ceiling.

The system works in Mode 3 for most of the operation time when the auxiliary cooling coils can be activated. When the lower thresholds for temperature and humidity ratio are reached, the system switches first to pure DEC operation (Mode 2) and then to indirect evaporative cooling (Mode 1) (This occurred at 6:30 PM in Fig. 4).

Temperature and humidity ratio values measured between 6:00 and 8:00 AM likely include some error because of the sensor's partial exposure to the sun. However, the system is still switched off for the mentioned time period.

Fig. 5 shows the energy performance of the solar collectors on the same day as shown in Fig. 4. As can be seen, the presence of heat storage allows delivery of heat to the regeneration coil until 7:00 $\mathrm{PM}$, when the system is finally switched off.

Daily performance indicators related to the exploitation of solar energy are shown in Fig. 6. It can be noted that the useful heat delivered by solar coil HC2 is about one third of the solar energy $\left(Q_{s o l}\right)$ on the collector surface. Solar collector efficiency is $39 \%$, which is a typical value for summer operation.

Fig. 7 illustrates the results for the heating process of the regeneration air stream on the same day. Air exiting the sensible heat exchanger at about $30-35{ }^{\circ} \mathrm{C}$ is heated in heating coil HC1 from the condensation heat of the refrigeration fluid, which reaches $40-42{ }^{\circ} \mathrm{C}$ during the operation of the chiller. Availability of condensation heat depends on the cooling demand for the radiant ceiling, and the two auxiliary cooling coils. Finally, the air passes through solar coil HC2 and reaches temperatures sufficient to regenerate the desiccant material. On the day presented, the maximum value was a temperature of about $60^{\circ} \mathrm{C}$.

The daily trend of $\mathrm{COP}_{\text {th }} \mathrm{HC} 1+\mathrm{HC}_{2}$ and $\mathrm{COP}_{\text {th }} \mathrm{HC2}$ for the DEC process (defined in Equation (3)) is shown in Fig. 8. This indicates the relationship between useful cooling power of the desiccant cooling process and regeneration heat. The daily average $\mathrm{COP}_{\text {th }}$ $\mathrm{HC} 1+\mathrm{HC} 2$ amounted to 0.53 , whereas the mean $\mathrm{COP}_{\text {th }} \mathrm{HC}$ taking into account only the solar heat was 0.67 . Maximum values are usually

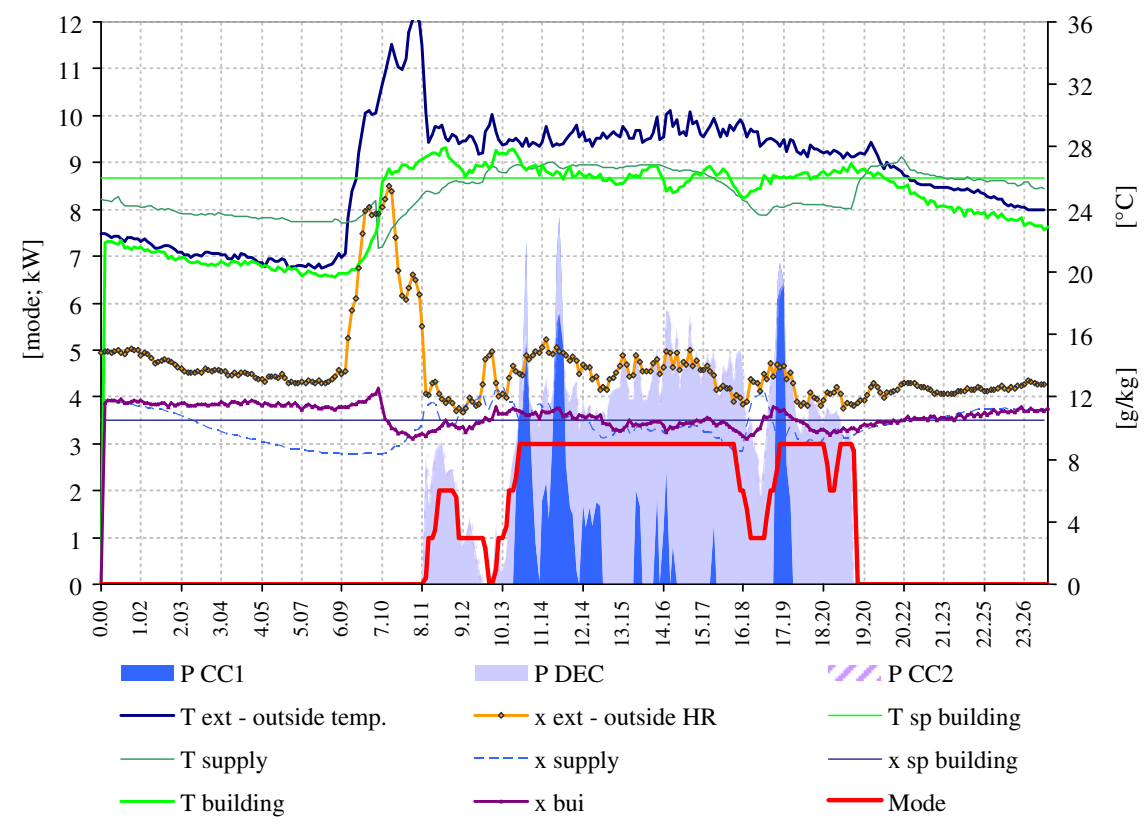

Fig. 4. Contribution of the desiccant cooling effect, Cooling Coil 1 and 2 (26 June 09). 


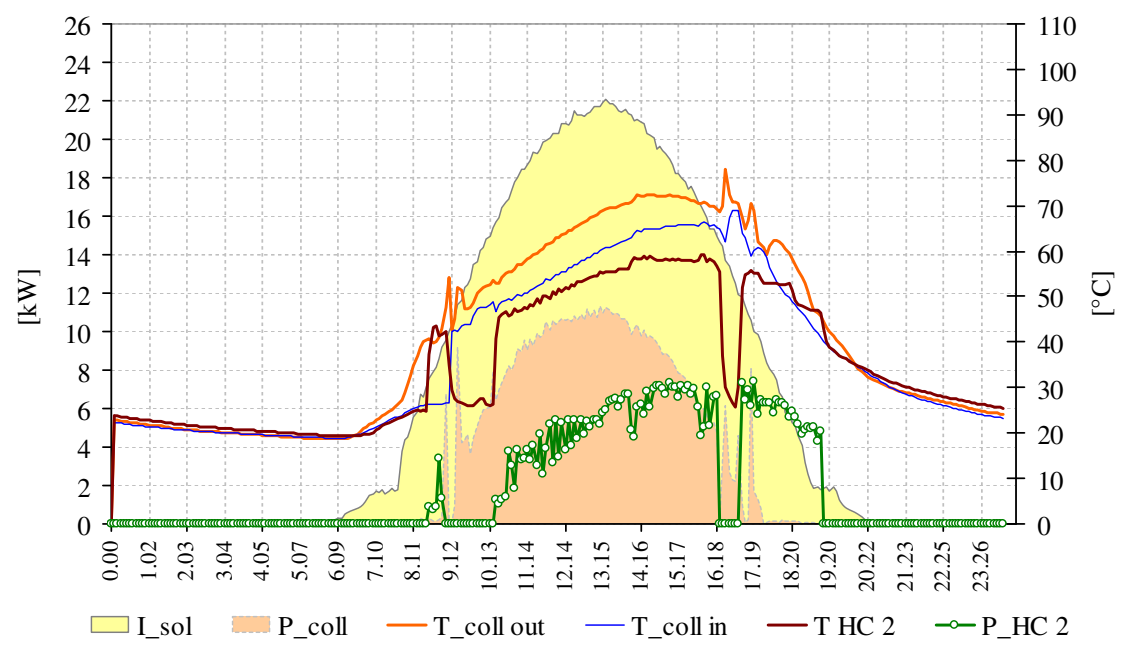

Fig. 5. Performance of solar collectors and regeneration heat (26 June 09).

achieved in the early afternoon, when regeneration temperatures rise to $60^{\circ} \mathrm{C}$.

Fig. 9 shows the $\mathrm{COP}_{e l}$ of the AHU on a summer day as a daily mean value of 1.94. Obviously, higher $\mathrm{COP}_{e l}$ can be reached when no auxiliary coil is active (in the early afternoon), as the cooling power is then delivered only by the desiccant cooling process.

Seasonal monitoring results for the months from June to September are presented in Fig. 10. The DEC process makes up 53\% of the total cooling energy delivered by the AHU. Electricity consumption of the auxiliary chiller (for the AHU demand) accounts for $44 \%$ of the total consumption, whereas $50 \%$ comes from the fans. The major contribution to regeneration heat comes from the solar coil HC2 (44\%), whereas the condenser coil HC1 accounts for $19 \%$. This interesting result shows the potential of using rejected condensation heat for regenerating the desiccant material.

\section{Winter operation: monitoring results on instantaneous, daily and monthly performances}

In winter operation, solar heat is used to feed the radiant ceiling and the heating coils in the AHU. Therefore, system boundaries are different, including energy flows related to the radiant ceiling. The control strategy for the AHU for heating is quite simple, with only

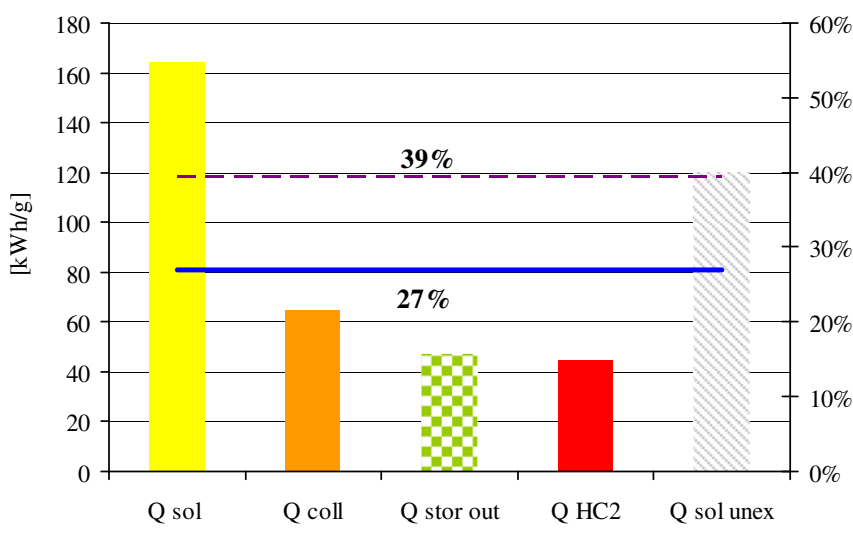

- solar heat manag. efficiency $\quad-\quad$ solar collector efficiency

Fig. 6. Exploitation of solar energy (26 June 09). two modes of operation: heat recovery (Mode -1) and active heating (Mode -2 ).

Some features of the system over one day of winter operation are presented below. Fig. 11 shows the heating power delivered to the building by the AHU, including the contributions of the heat exchanger, heating coil and radiant ceiling.

On this day, the system operated in active mode (Mode -2) until $11 \mathrm{AM}$, when the AHU switched to ventilation mode (Mode 0) because the radiant ceiling was able to meet the heating load. Fig. 12 shows performance concerning the heat delivered by the solar collectors and gas boiler. From 10:30 AM to 3:00 PM, the system was able to meet the heating load of the building even though available solar radiation was quite low, with the solar collectors contributing about $30 \%$ of the total heat.

Electrical COP of the whole system, including electricity consumption of the AHU, pumps and accessories, is shown in Fig. 13. An average COP of about six was achieved for the considered day.

Seasonal monitoring results for the heating season are presented in Fig. 14. Months considered in the calculations are December 2009, January and February 2010. First of all, it can be noted that the total heating energy delivered during the winter season (4063 kWh) was about two-fifths of the cooling energy delivered by the system to the building during summer operation (10,351 kWh). This shows the relative importance of cooling and heating operations for this specific building and climate.

The system reached a solar fraction of $44 \%$ of the total heat produced, whereas heat losses of the storage amounted to $11 \%$. The contribution of heat recovery to the total heat required was about $18 \%$, corresponding to $37 \%$ of the total energy delivered by the AHU. More than three quarters of the electricity consumed was by the fans.

\section{Monitoring results according to the Task 38 IEA unified procedure}

In the framework of the above-mentioned IEA Task 38, a unified monitoring procedure was developed to permit seasonal and yearly comparisons among several solar cooling and heating plants. This can be accomplished through a common evaluation methodology of energy performance, similar to that for conventional air conditioning systems [18,19]. Fig. 15 shows the energy flow scheme defined in this procedure, adapted to the system presented.

As mentioned previously, energy flows related to the radiant ceiling in cooling operation were not included in the calculation of 


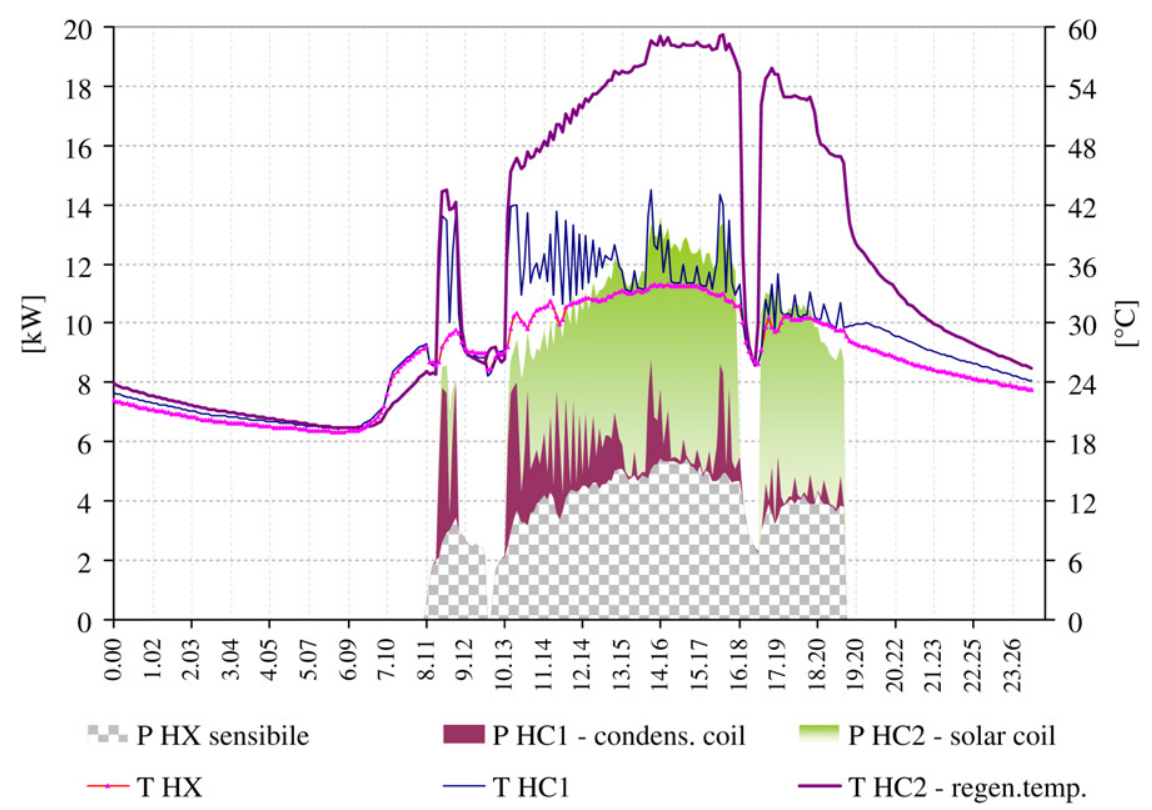

Fig. 7. Regeneration power of the AHU components Heat exchanger HX, Heating Coil HC 1 and HC 2 (26 June 09).

performance indicators presented below. The choice to leave this out of the energy balances was due to the fact that it only operates with conventional cooling power (vapour compression chiller). In this way, performance of the solar desiccant AHU can be evaluated better and presented clearly. Finally, the gas boiler operates only in the winter as a backup energy source.

The procedure used to evaluate performance of the system can be divided into three levels. The first contains basic information on provided measurements and calculation of the Primary Energy Ratio (PER). The second level aims to analyse performance of the solar plant. In the third level, additional comparisons with a reference plant are carried out. Some basic assumptions in the calculations include $\varepsilon_{\mathrm{el}}=0.40, \eta_{\text {boiler }}=0.95, \eta_{\text {fossil }}=0.90$.

The first performance indicator is the PER; that is, the cooling or heating energy produced with $1 \mathrm{kWh}$ of primary energy. For a DEC system, it can be defined as the following:

$P E R_{D E C \text { Cooling }}=\frac{\Delta H_{A H U}}{E_{e l} / \varepsilon_{e l}}[-]$

where $\Delta H_{A H U}$ is the total cooling/heating energy delivered by the AHU and defined with the following formula:

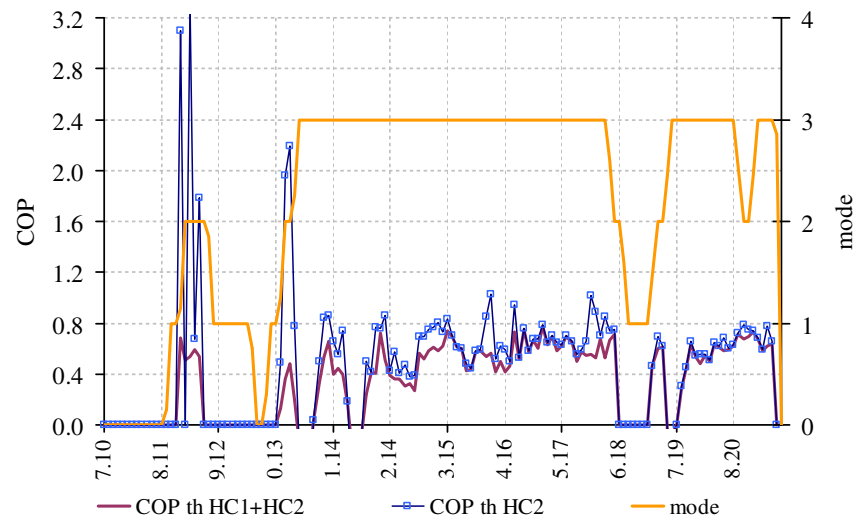

Fig. 8. Thermal COP of the AHU (26 June 09).
$\Delta H_{A H U}=\sum_{t}\left[\dot{m}\left|h_{\text {ext }}-h_{\text {sup ply }}\right| \Delta t\right][\mathrm{kWh}]$

The term $E_{e l}$ is the electricity consumption of the DEC part of the AHU, including only electricity consumption due to typical components used in the DEC cycle (desiccant wheel, sensible heat exchanger, humidifiers, solar pump, etc.) and excluding electricity consumption due to components used for water and air distribution that would also be present in a conventional AHU.

In winter operation, the formula used for the calculation of PER is written as the following:

$P E R_{D E C \text { Heating }}=\frac{Q_{\text {out storage }}}{E_{\text {el }} / \varepsilon_{\text {el }}+E_{\text {heat aux }} /\left(\eta_{\text {boiler }} \cdot \eta_{\text {fossil }}\right)}[-]$

where $Q_{\text {out }}$ storage is the total useful heat (the measured heat extracted from storage and now delivered to the heating coil of the AHU and to the radiant ceiling) and $E_{\text {heat aux }}$ is the heat delivered to storage by the auxiliary gas boiler.

Fig. 16 presents monthly values for the system's PER and electric COP. The lower value of PER in September can be explained by the

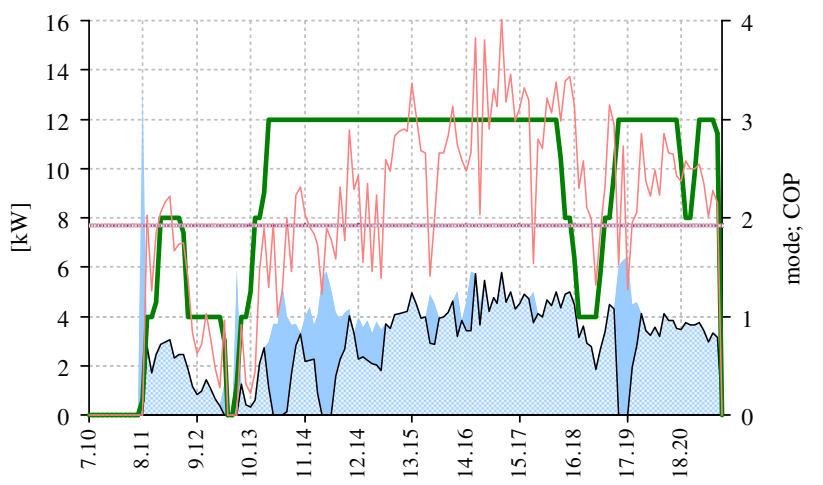

P AHU $\square$ P DEC — mode $\longrightarrow$ COP el AHU nmmom COP el AHU average

Fig. 9. Cooling power, operation mode and electric COP of the AHU (26 June 09). 
Electricity consumption AHU [kWh]

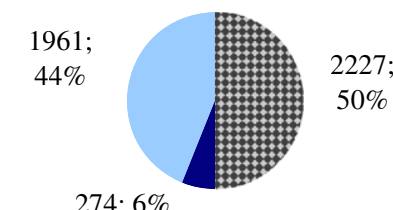

AHU aUX chiller

Regeneration heat [kWh]

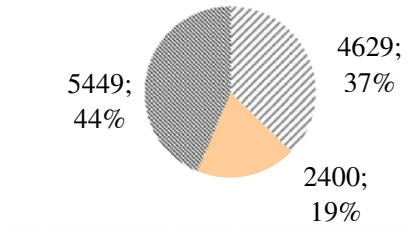

\%QHX ret $\square$ Q HC $1 \backsim$ Q HC 2
Cooling energy produced in the AHU

[kWh]

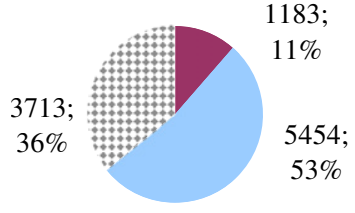

$\square \mathrm{QCC} 1 \quad$ Q DEC $\quad \mathrm{QCC} 2$

Tank losses [kWh]

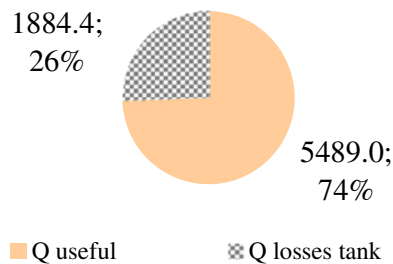

Fig. 10. Seasonal monitoring results, cooling operation.

fact that the cooling energy demand of the building was lower, while electricity consumption by fans and auxiliaries remained the same. The $\mathrm{COP}_{e l}$ of the AHU calculated from Equation (4) ranges from 1.8 to 2.6 for cooling operation (the average value for cooling was 2.4) and from 3.5 to 5.5 for heating operation (the average value for heating was 4.7 ).

The second level of the procedure deals with exploitation of solar energy for heating and cooling. In Table 2, the main performance indicators calculated from Equations (5)-(8) are reported.

Collector efficiency in summer and winter operation is obviously different, with a seasonal average value of about $40 \%$ for summer operation. On the other hand, storage efficiency in winter is higher due to lower operation temperatures. Solar heat management efficiency in summer and winter operation is nearly the same, ranging from $27 \%$ to $29.4 \%$. This shows a correlation between heat demand and solar irradiation.

In the third level of the monitoring procedure, the primary energy saving potential of the system was investigated. Comparison of a desiccant evaporative cooling system with other solar cooling systems such as ab-/adsorption cooling systems is a difficult task due to differences from typical water refrigeration machines.

A fair comparison of a DEC system with a conventional AHU coupled with a compression chiller can be done properly by considering the different thermodynamic processes realized in the two systems.

In Fig. 17, the air handling capabilities of the DEC and a conventional AHU are shown on a psychrometric chart. In a conventional system, additional cooling energy is needed for the dehumidification process to reach dew point temperatures, with consequent re-heating of the air up to the desired inlet temperature conditions. This additional cooling and heating energy required in a conventional AHU ( $\Delta H_{\text {conv }} C C$ and $\left.\Delta H_{\text {re-heating }}\right)$ must be considered to properly calculate the primary energy savings of the DEC system. For calculation of the heating energy due to the re-heating process, the hypothesis of reaching a supply temperature of $20^{\circ} \mathrm{C}$ was assumed $\left(\Delta H_{\text {corr }}\right.$ is the difference between the

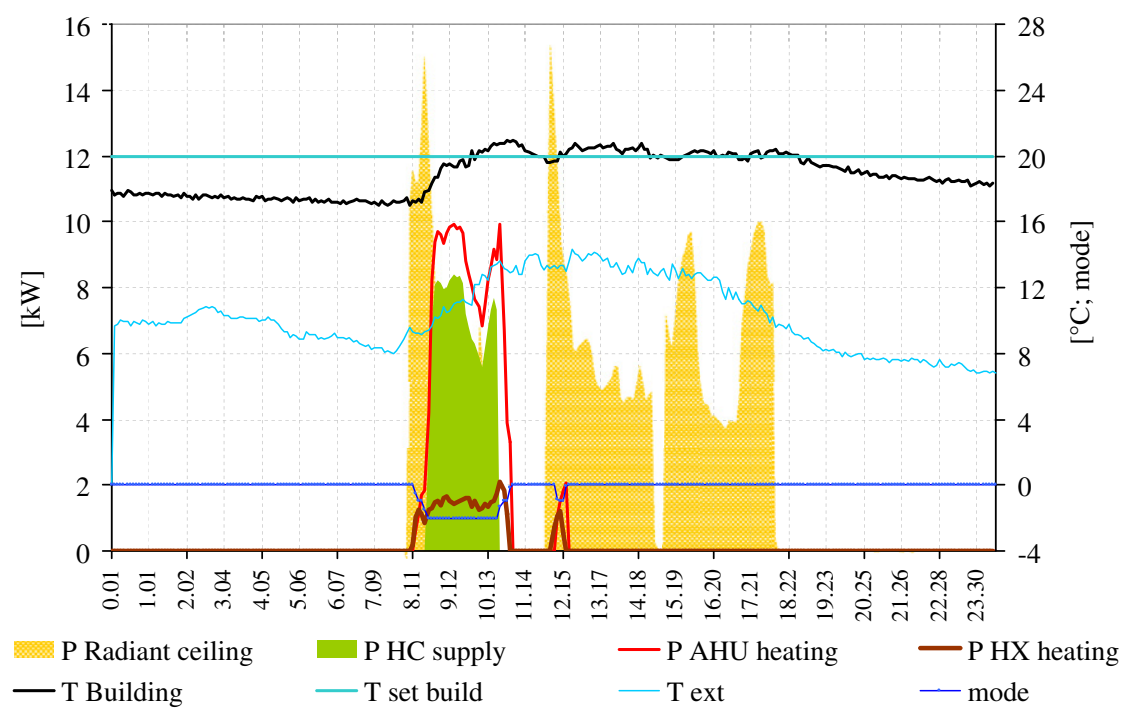

Fig. 11. Heating operation of the AHU and radiant ceiling (19 January 10). 


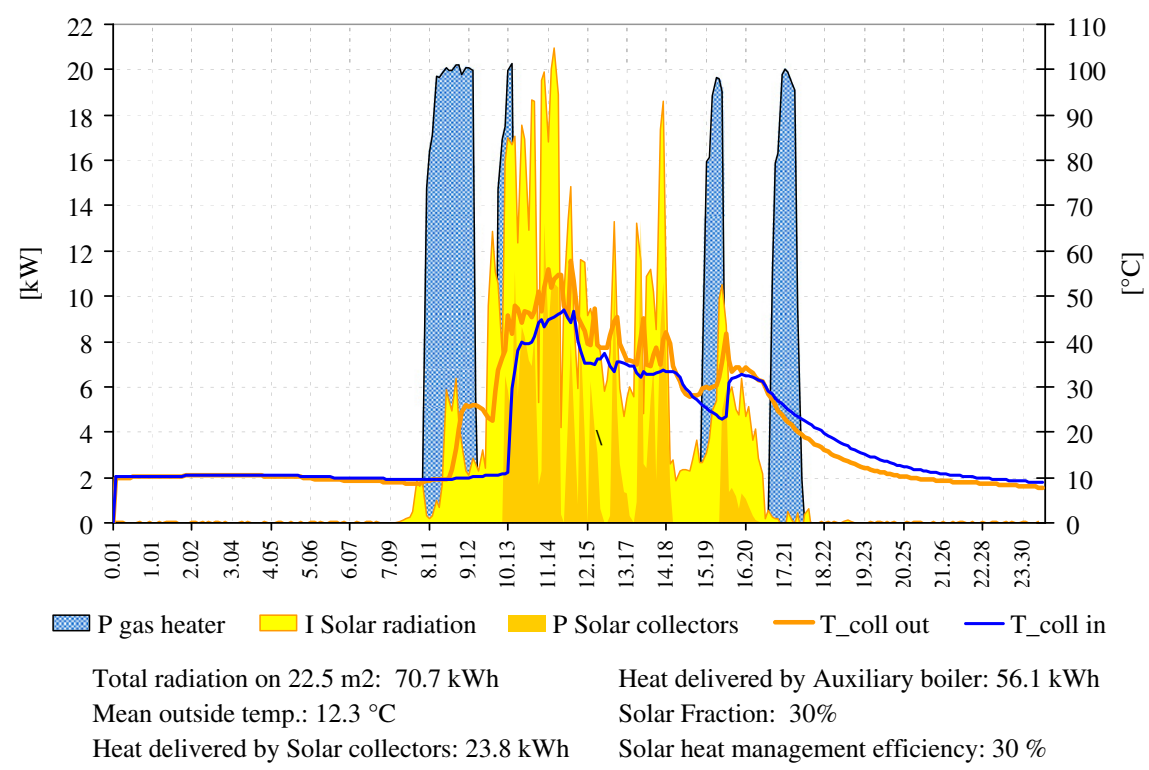

Fig. 12. Solar collectors and auxiliary gas boiler (19 January 10).

supply air enthalpy of the DEC and the one of the conventional AHU). A schematic of the reference system used in this procedure is shown in Fig. 18.

Primary energy savings obtained by the DEC system in comparison to a reference conventional system are shown in Fig. 19. Not considering the additional cooling and heating energy required in a reference conventional AHU would result in a considerable underestimation of the energy saving potential of DEC systems. A primary energy savings for cooling operation of 49.2\% was achieved after considering the additional cooling and heating energy required in the reference conventional AHU. Without this part, the primary energy saving calculated is about $33.6 \%$. In heating operation, the mean value of primary saving amounts to $26.6 \%$.

The thermal COP of the AHU, calculated according to Equation (3) and referring to the solar heating coil, ranged significantly from
0.63 to 1.23 , due to the differences in required dehumidification power. The average value was 1.0.

\section{Remarks and lessons learned}

The main aspects observed through the monitoring and the evaluation of the system are summarized below. The use of a heat recovery coil connected to the compressor of the cooling machine was found as good solution for preheating the regeneration airflow and for achieving a reduction of solar heat demand. This permits a reduction of the solar collector area in the design, especially if the auxiliary chiller is also often used to provide cooling to other equipment (fan coils, radiant ceiling, etc.). A further advantage of this configuration is the correlation between cooling power demand and heat rejection at the condenser. In addition, due to the higher chilled water temperature required both by the chilled

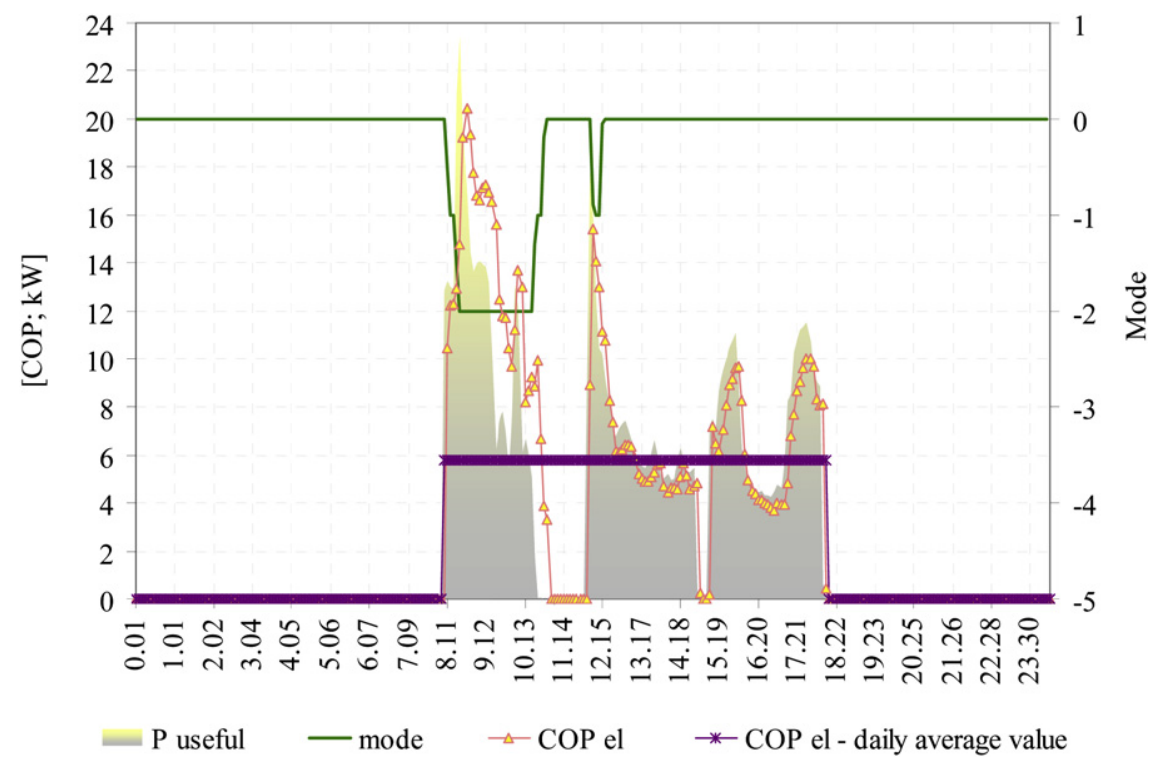

Fig. 13. Electric COP of the system (19 January 10). 
Heat produced in $\mathrm{kWh}$ and

Solar Fraction

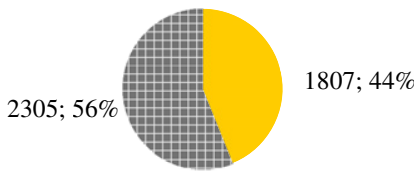

Solar Collectors $\quad$ in Auxiliary Heater

Electricity consumption [kWh]

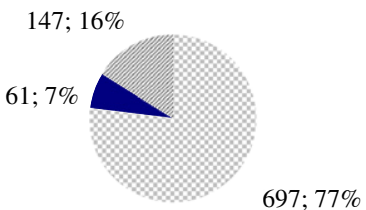

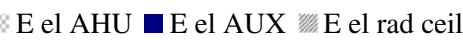

Heat delivered to the building [kWh]

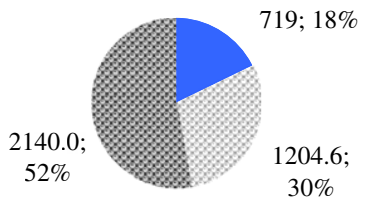

aX $\approx$ Heating Coil $\%$ Radiant ceiling

Tank losses [kWh]

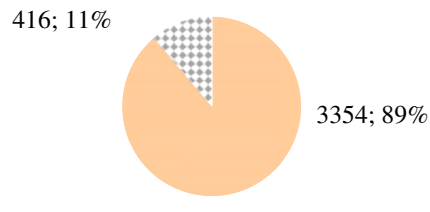

Q useful : Q losses tank

Fig. 14. Seasonal monitoring results - heating operation.

ceiling and auxiliary cooling coils (about $12{ }^{\circ} \mathrm{C}$ ), an increase of the cooling capacity and COP of the chiller was also achieved. The contribution of the recovery coil $\mathrm{HC} 1$ to the total regeneration process was about $20 \%$, which corresponds to about $30 \%$ of the heat delivered by $\mathrm{HC} 1$ and $\mathrm{HC} 2$.

The choice to install a high-performing desiccant wheel increased the dehumidification capacity even with regeneration air temperature below $70^{\circ} \mathrm{C}$ and a bypass ratio of two-thirds between the regeneration and process airflow.

Observations during the monitoring of the system have also revealed some unfavourable aspects that have to be considered. First of all, fan electricity consumption of the desiccant unit is much higher than for a conventional AHU operating with the same flow rate. This is due to higher total pressure drops across the unit. This aspect has to be considered during the design and selection of each component of the AHU. For example, additional air intakes can be used in the AHU to reduce the total pressure drop if some components are not needed for a certain mode of operation. The use of inverters can also reduce the electricity consumption by air circulation, and auto flow pumps can reduce the energy consumption by water circulation.

It was found that the use of a rotating heat exchanger can cause carry-over of water vapour from the return to the process air side of the desiccant AHU. Detailed humidity measurements up- and downstream of the rotating heat exchanger have shown that the dehumidification capacity of the whole desiccant unit can be

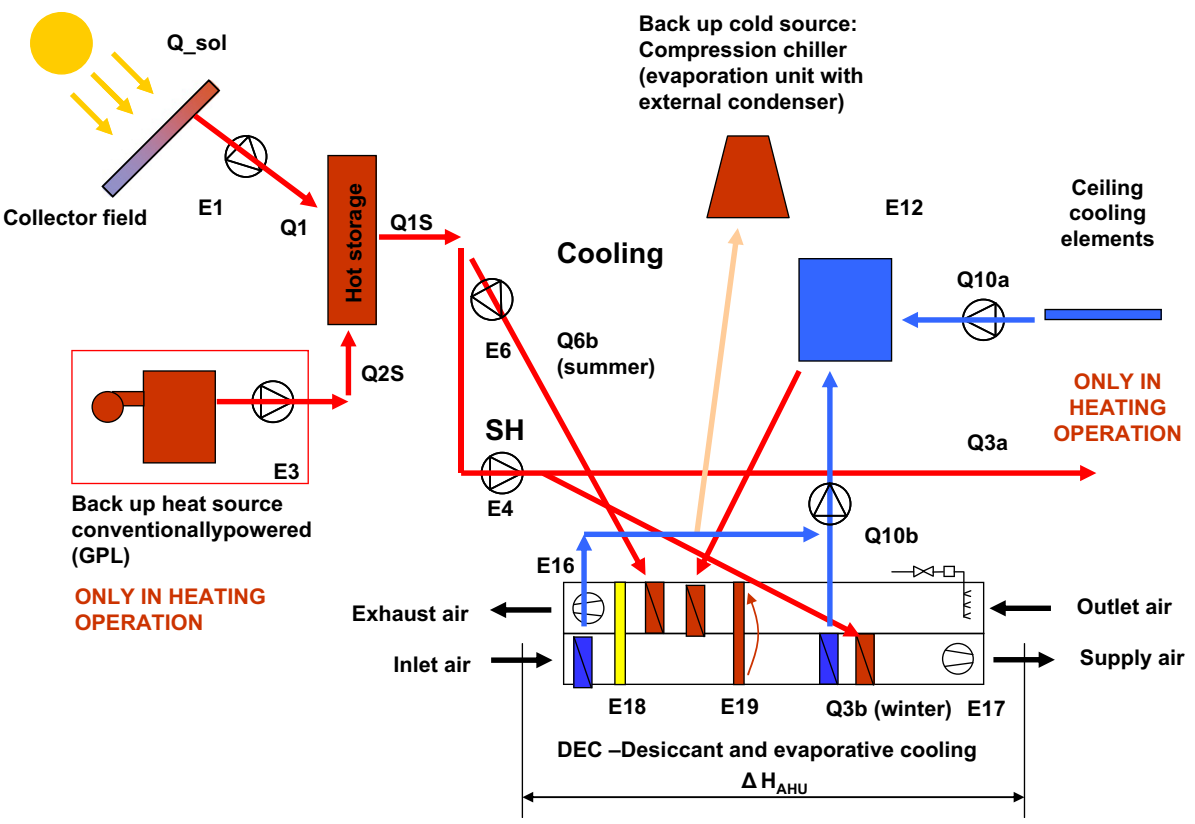

Fig. 15. Scheme of plant according to the monitoring procedure IEA Task 38. 


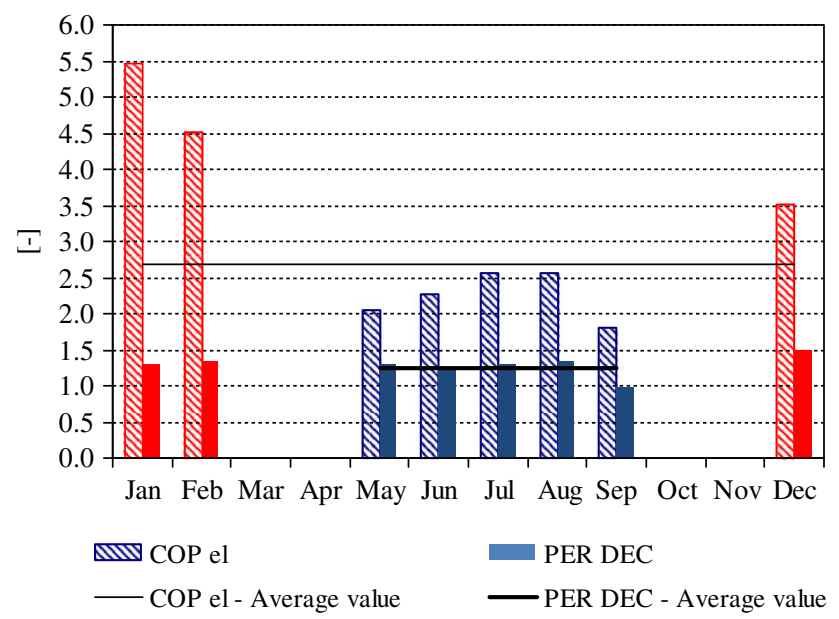

Fig. 16. Monthly values of PER and electric COP for the DEC system.

Table 2

Seasonal performance indicators of the solar system.

\begin{tabular}{lcl}
\hline & $\begin{array}{l}\text { Cooling } \\
\text { operation }\end{array}$ & $\begin{array}{l}\text { Heating } \\
\text { operation }\end{array}$ \\
\hline Collector efficiency [\%] & 39.9 & 36.8 \\
Solar Fraction of hot storage [\%] & 100 & 43.9 \\
Storage efficiency [\%] & 70.3 & 81.5 \\
Solar heat management efficiency [\%] & 27.0 & 29.4 \\
\hline
\end{tabular}

strongly affected by this process. Moisture carry-over can affect energy performance of the system by reducing the dehumidification potential of the desiccant unit, leading to a greater use of the auxiliary cooling coils. This can be reduced by improving or substituting the sealing devices in the heat exchanger. This phenomenon can also be caused by dust deposition on the internal surface of the channels in the heat exchanger. Therefore, it is suggested to periodically check the efficiency of the filters. For smallsized AHUs, a plate heat exchanger may be preferable to a rotating one.

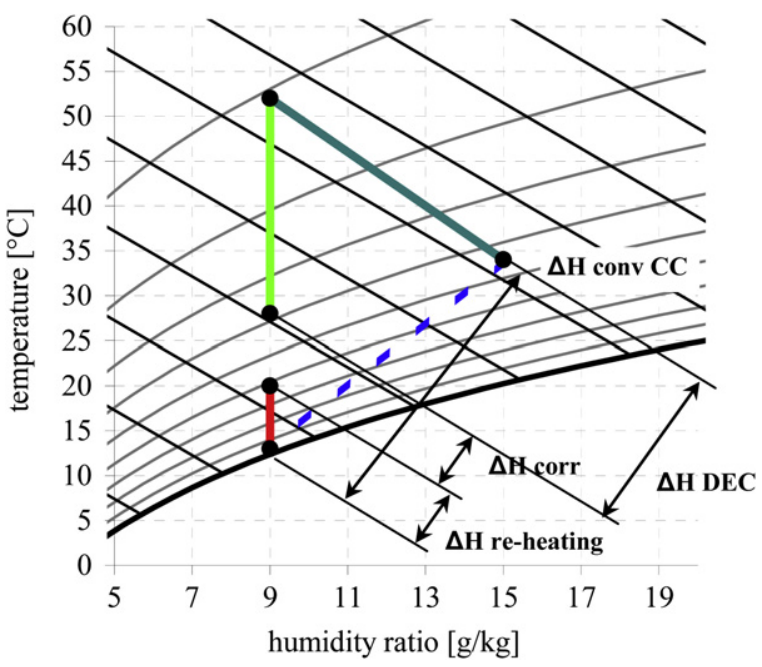

Fig. 17. Mollier diagram of a typical DEC and conventional AHU cycle.

Improvements to the control strategy after one season of operation allowed better system performance. For instance, in the starting-phase humidity control strategy of the predehumidification coil $\mathrm{CC} 1$ was set up to maintain the humidity ratio at the outlet of the CC1 below a certain threshold, avoiding an overload of the desiccant wheel. This control strategy could not also maintain good comfort conditions in the room, as measured by the humidity ratio. Therefore, a change in the control strategy was made so the coil is now controlled on the basis of the humidity ratio measured in the room. After this change, better humidity control of the room was experienced.

The flow rate in the solar loop is higher in heating than in cooling operation. In winter, high flow operation of the solar pump can guarantee higher efficiency of the collectors, since the required supply temperature is quite low (about $40^{\circ} \mathrm{C}$ ). A low-flow operation was chosen during the summer season in order to get a higher regeneration air temperature.

Finally. thermal energy losses in the storage observed in the start up phase were higher than expected, showing a need for improvement of the insulation for the storage.

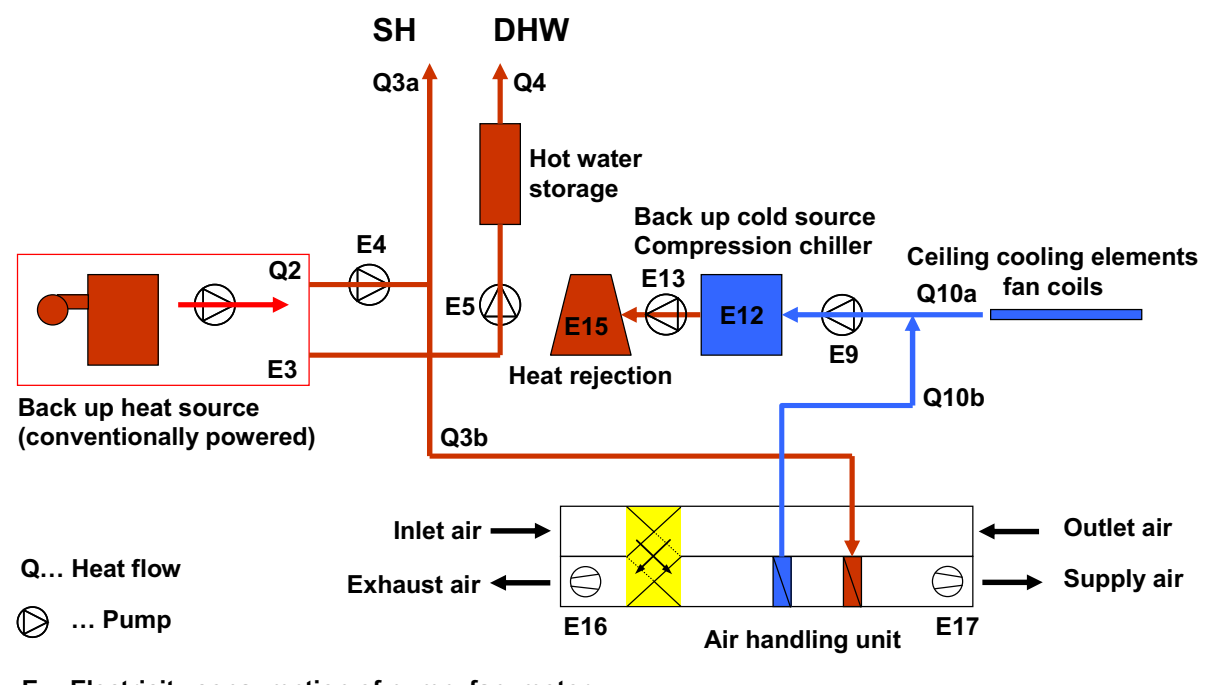

E... Electricity consumption of pump, fan, motor, ...

Fig. 18. Reference conventional system according to the monitoring procedure IEA Task 38. 


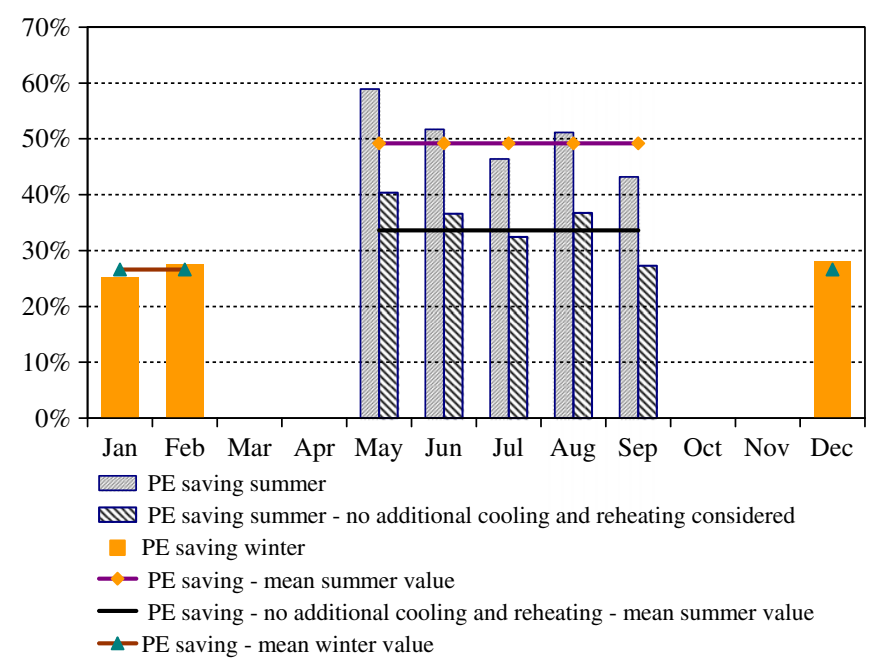

Fig. 19. Primary Energy Savings of the DEC system in comparison to the reference conventional system.

\section{Conclusions}

A detailed assessment of monitoring results of a solar desiccant evaporative cooling system in south Italy was carried out, and instantaneous, monthly as well as seasonal performance indicators are presented and discussed. System evaluation was conducted according to the monitoring procedure developed, with the contribution of the authors, in the framework of IEA Task 38 "Solar Air Conditioning and Refrigeration".

Monitoring results obtained for the cooling season show that the contribution of evaporative desiccant cooling effect achieved $53 \%$ of the total cooling energy delivered by the AHU. The Electric COP during summer operation was 2.4 if the total cooling energy produced and the total electricity consumed are considered. The COP was 4.4 if only the electricity consumption and cooling energy related to the DEC process are considered.

The use of heat rejected by the chiller to preheat regeneration airflow allowed a reduction of the solar collector area by about $30 \%$. Therefore, due to the heat recovery, a seasonal value of 1.0 for the thermal COP of the system was measured.

The primary energy savings calculated for the DEC system strongly depends on assumptions made about the reference system. Since the DEC and conventional thermodynamic cycles are very different, a detailed evaluation of the additional cooling and heating energy required by the reference $\mathrm{AHU}$ is needed for a fair comparison between the two systems. According to this approach, primary energy savings achieved by the DEC system in comparison to the reference conventional AHU come up to $49.2 \%$ if additional cooling for the dehumidification and the re-heating process are considered. This comparison approach shows the enormous energy saving potential of the solar DEC technology in the air conditioning sector.

The total heating energy delivered by the system during the winter season is about two-fifths of the seasonal delivered cooling energy. Solar fraction and consequent primary energy savings in winter operation are appreciable, being respectively $44 \%$ and $27 \%$.

Some weaknesses observed are related to the sensible heat exchanger used, where humidity from return air is carried over to the process air, reducing the dehumidification capacity of the DEC system. Another issue to be investigated with more detail in the future is the influence of temperature and flow rate of regeneration air on the dehumidification capacity of the desiccant wheel. Suitable modifications to the system configuration have already been realized, and new monitoring results will be presented in future works.

\section{Acknowledgements}

This work has been carried out in the framework of the Research Plan "R\&D activities of general interest for the National Electric System" funded by the Italian Ministry of Economic Development (MSE). The subtask was co-ordinated by Marco Citterio (ENEA) and Marco Beccali (Unipa-Dipartimento di Energia).

\section{References}

[1] Pennington NA. Humidity Changer for Air Conditioning. U.S. patent No. 2,700,537, 1955 .

[2] Munters CG. Air conditioning System. U.S. Patent No.2, 926, 502, 1960.

[3] Henning HM. Solar-Assisted air-conditioning of buildings - an overview. Applied Thermal Engineering 2007;27:1734-49.

[4] Henning HM. Solar-Assisted Air-Conditioning in Buildings - A Handbook for Planners. Wien, New York: Springer; 2004.

[5] Mazzei P, Minichiello F, Palma D. HVAC dehumidification systems for therma comfort: a critical review. Applied Thermal Engineering 2005;25:677-707.

[6] Daou K, Wang RZ, Xia ZZ. Desiccant cooling air conditioning: a review. Renewable and Sustainable Energy Reviews 2006;10:55-77.

[7] Jain S, Dhar PL, Kaushik SC. Evaluation of solid-desiccant-based evaporative cooling cycles for typical hot and humid climates. International Journal of Refrigeration 1995;18/5:287-96.

[8] Ginestet S, Stabat P, Marchio D. Control Strategies of open cycle Desiccant Cooling Systems minimising energy consumption. eSim 2002, The Canadian conference on building energy simulation, Montréal, 11-13 Sept 2002.

[9] Finocchiaro P, Analisi numerica di sistemi Desiccant Cooling alimentati ad energia solare per applicazioni in climi mediterranei - PhD thesis - Università degli Studi di Palermo, 2007.

[10] Henning HM, Mola S, Menardi L, Pagano T, Wiemken E. Micro tri-generation system for indoor air conditioning in the Mediterranean climate. In: Proceedings of 3rd International Conference on Heat Powered Cycles, Cyprus 2004.

[11] Beccali M, Finocchiaro P, Nocke B. Solar desiccant cooling systems with single glazed air and hybrid PV/thermal solar collectors for applications in the Mediterranean climate. Solar Energy 2009;83:1828-46.

[12] Thuer A. Solar heating and cooling -Town hall Gleisdorf. In: Proceedings of the 3rd International Conference solar Air-Conditioning, Palermo (I), 30 Sept-2 Oct 2009.

[13] Bader T, Finkenzeller M, Trinkl C, Zörner W. In-Situ Measurements, Simulation and System Optimization of a solar-driven DEC-System in an Industrial Environment. IN: Proceedings of the 3rd International Conference Solar AirConditioning, Palermo (I), 30 Sept-2 Oct 2009.

[14] Bourdoukan P, Wurtz E, Joubert P. Experimental investigation of a solar desiccant cooling installation. Solar Energy 2009;83:2059-73.

[15] Beccali M, Finocchiaro P, Luna M, Nocke B. Monitoring of a solar desiccant cooling system in Palermo (Italy), First results and test planning. In: Proceedings of the International Conference EUROSUN 2008, Lisbon (P), 7-10 Oct 2008.

[16] Beccali M, Finocchiaro P, Nocke B. Solar desiccant cooling system operating in Palermo (Italy): results and validation of simulation models. In: Proceedings of the 3rd International Conference Solar Air-Conditioning, Palermo (I), 30 Sept-2 Oct 2009, pp. 368-375.

[17] Beckman WA, et al. TRNSYS, Reference Manual. Madison, USA: Solar Energy Laboratory; 2001.

[18] Sparber W, Napolitano A Besana F, Thür A, Nocke B, Finocchiaro P, Nieto L.A Bujedo, Rodriguez V, Nùnez T. Comparative results of monitored solar assisted heating and cooling installations. In: Proceedings of the 3rd International Conference Solar Air-Conditioning, Palermo (I), 30 Sept-2 Oct 2009.

[19] Nocke B, Monitoraggio e valutazione energetica di un impianto sperimentale Desiccant Cooling - PhD thesis - Università degli Studi di Palermo, 2009. 